\title{
Simulation of the shock waves propagation through the interface of bipartite bimetallic Ni-Al particles
}

\author{
P. V. Zakharov ${ }^{1,2, \dagger}$, G. M. Poletaev², M. D. Starostenkov², A. I. Cherednichenko' \\ ${ }^{1}$ The Shukshin Altai State Humanities Pedagogical University, 53 Korolenko str., 659333, Biysk, Russia \\ ${ }^{2}$ Altai State Technical University, 46 Lenin ave., 656038, Barnaul, Russia
}

By means of molecular dynamics method, structural changes in Ni-Al bimetal particles during the propagation of shock waves were studied. A possibility of pore formation near the interface between the metals was established. It was found that determining factors of the pore formation near a Ni-Al interface were the mutual orientation of the metals, their size and the direction of a shock wave propagation. Two directions of the shock wave propagation were considered. In the first case, the wave was initiated on the Ni side. If the direction of the wave motion coincides with the close-packed direction in the crystal, detachment of a part of the atoms from the $\mathrm{Al}$ surface with a subsequent formation of clusters of these atoms was possible. In this case, the surface attained a typical shape with a dimple in the center of the particle. If the shock wave propagates along a not close-packed direction, the main part of its energy dissipated near the metal interface and led to the formation of pore nuclei. The formation of the pores depended mainly on the bimetal particle size. The dependence of the maximum pore size on the linear dimensions of the Ni-Al bipartite bimetal particles was calculated. Time evolution of the pores was studied. In the second case, the shock wave was initiated from the Al side. Similar effects were obtained. However, the pores were formed on the Al but and not on the Ni side. Such a location of the pores was due to a lower binding energy between $\mathrm{Al}$-Al atoms than between $\mathrm{Ni}-\mathrm{Ni}$ and $\mathrm{Ni}-\mathrm{Al}$ ones. When the shock wave passed along close-packed directions, the energy was not sufficient to detach the atoms from the Ni side and form clusters of them.

Keywords: bimetal, shock wave, pore, fcc crystal, misfit dislocation.

\section{Моделирование прохождения ударных волн через границу раздела двудольных биметаллических частиц $\mathrm{Ni}-\mathrm{Al}$}

\author{
Захаров П. В. ${ }^{1,2,}$, Полетаев Г. М. ${ }^{2}$, Старостенков М. Д. ${ }^{2}$, Чередниченко А.И. ${ }^{1}$ \\ †zakharovpvl@rambler.ru
}

\author{
${ }^{1}$ Алтайский государственный гуманитарно-педагогический университет им. В.М. Шукшина, ул. Короленко 53, \\ 659333, г. Бийск, Россия \\ ${ }^{2}$ Алтайский государственный технический университет, пр. Ленина 46, 656038, г. Барнаул, Россия
}

\begin{abstract}
Методом молекулярной динамики изучены структурные изменения частиц биметаллов $\mathrm{Ni}-\mathrm{Al}$ при прохождении ударных волн. Показана возможность формирования зародышей пор вблизи поверхности раздела металлов. Установлено, что определяющими факторами формирования зародышей пор вблизи границы раздела Ni-Al являются взаимная ориентация металлов, их размер и направление прохождения ударной волны. Рассмотрены два направления прохождения ударной волны. В первом случае волна инициировалась на стороне Ni. Если направление движения волны совпадало с плотноупакованным направлением в кристалле, то был возможен отрыв части атомов с поверхности Al с последующим формированием из них кластеров. Поверхность приобретала характерную форму с углублением в центре частицы. В случае распространения ударной волны вдоль не плотноупакованного направления, основная часть энергии рассеивалась вблизи границы раздела металлов и приводила к формированию зародышей пор. Формирование пор в большей степени зависело от размеров частиц биметалла. Рассчитана зависимость максимального размера пор от линейных размеров частиц двудольного биметалла Ni-Al. Рассмотрена эволюция пор с течением времени. Во втором случае ударная волна инициировалась со стороны Al. Были получены аналогичные эффекты, однако, поры формировались со стороны Al, а не со стороны Ni. Такое расположение пор обусловлено меньшей энергией связи между атомами Al-Al, чем между $\mathrm{Ni}-\mathrm{Ni}$ и $\mathrm{Ni}-\mathrm{Al}$. При прохождении ударной волны вдоль плотноупакованных направлений энергии было недостаточно для отрыва атомов со стороны Ni и формирования из них кластеров.
\end{abstract}

Ключевые слова: биметалл, ударная волна, пора, ГЦК кристалл, дислокация несоответствия. 


\section{1. Введение}

Износостойкие и инструментальные биметаллы находят все большее применение в деталях машин, подвергающихся сильному износу. Антифрикционные биметаллы уже давно используются для производства подшипников скольжения. Активно применяются проводниковые и контактные биметаллы. Биметаллы для глубокой вытяжки сочетают в себе наряду с высокой прочностью и достаточной пластичностью хорошую теплопроводность и коррозионную стойкость $[1,2]$. В свою очередь с переходом к нано-размерным материалам резко возрос теоретический и экспериментальный интерес к биметаллическим наночастицам. Уникальные физические и химические свойства биметаллических частиц связаны с их структурными, электронными и оптическими свойствами [3].

Структура биметаллических наночастиц определяется распределением в ней металлов. Частицы могут быть организованы в виде упорядоченного сплава, например двудольные биметаллы (ДБМ), иметь произвольный состав, либо иметь архитектуру типа «ядро-оболочка». Последний тип реализуется только на наноуровне и представляет собой частицы одного металла, покрытые другим.

Такие материалы привлекают значительный исследовательский интерес в связи с их потенциальным применением в области гетерогенного катализа, так как они часто более активны по сравнению со своими монометаллическими аналогами. Улучшение свойств этих систем связывают со сложным взаимодействием электронов двух металлов и эффектами изменения параметров решетки в биметаллических сплавах или на межфазных границах двух металлов $[4,5]$. Особый интерес вызывают соединение $\mathrm{Ni}-\mathrm{Al}$.

Биметаллические соединения $\mathrm{Ni}-\mathrm{Al}$ применяются для получения многослойных углеродных нанотрубок из полипропилена [6] и других соединений [7]. Биметаллические нанокластеры имеют практическое значение для формирования токовых и потенциальных контактов в элементах электроники в связи с тем, что работа выхода электронов сильно зависит от реальной структуры биметаллов. Кроме того, тонкие покрытия $\mathrm{Ni}-\mathrm{Al}$ активно используются для реактивного химического сращивания (бондинга) полупроводниковых структур в многослойные интегральные схемы с целью повышения плотности упаковки отдельных элементов за счет реализации трехмерной архитектуры [8-10].

Биметаллические соединения, в виду их применения в различных технологических процессах, могут подвергаться различным интенсивным внешним воздействиям, что может приводить к энергетическим и структурным трансформациям, которые в свою очередь влияют на свойства таких частиц. Умение управлять свойствами и структурой наноразмерных частиц является важной задачей современного материаловедения. Одним из механизмов управления структурой биметаллических частиц может быть воздействие потока высокоэнергетических частиц на твердое тело, сопровождающееся образованием ударных послекаскадных волн, форми- рующихся в результате резкого расширения сильно разогретой каскадной области.

В ряде работ показано, что ударные волны могут влиять на процессы самодиффузии в ГЦК кристаллах [11], вызывать укрупнение вакансионных пор [12, 13], а так же участвовать в ряде других процессов $[14,15]$.

Инициирование ударных волн может быть осуществлено посредством мощного лазерного излучения, при значениях интенсивности в пределах $10^{12}-10^{13} \mathrm{~B} / \mathrm{cm}^{2}$, либо при бомбардировке поверхности металла тяжелыми ионами $[16,17]$.

Отметим также, что актуальность данного исследования обусловлена необходимостью создания радиационностойких конструкционных материалов, способных работать в экстремальных условиях без значительного изменения своих свойств. Размерная нестабильность, проявляющаяся в виде явлений радиационной ползучести или радиационного распухания, обусловлена развитием новой дефектной структуры в результате переползания дислокаций, а также роста пор [18].

Таким образом, в данной работе проводится исследование прохождения ударных волн через границу раздела двудольного биметалла $\mathrm{Ni}-\mathrm{Al}$.

\section{2. Методика моделирования}

Исследуемые в работе процессы отличает высокая скорость протекания, что затрудняет прямые наблюдения. В натурных экспериментах по изучению ударных волн в металлах, зачастую, рассматриваются начальные и конечные состояния без исследования кинетики процесса. Для более детального понимания сути таких процессов необходимо их рассмотрение в динамике. Поэтому оптимальным видится использование методов компьютерного моделирования. В качестве метода компьютерного моделирования был выбран метод молекулярной динамики, в связи с тем, что он позволяет проводить эксперименты с заданными скоростями атомов и описывать динамику исследуемых процессов в реальном времени. Данный метод хорошо себя зарекомендовал при изучении процессов на границе раздела фаз металлов и сплавов [19-21].

Моделирование производилось с использованием хорошо зарекомендовавшего себя пакета молекулярной динамики - LAMMPS [22]. Данный пакет разрабатывался для применения к расчетам на параллельных компьютерах. В качестве межатомного потенциала использовался потенциал, полученные методом погруженного атома (EAM) и входящие в стандартный набор LAMMPS, предложенный авторами работы [23]. Полная энергия кристалла $E$ может быть выражено как:

$$
E=1 / 2 \sum_{i, j, i \neq j} \varphi_{i j}\left(r_{i j}\right)+\sum_{i} F_{i}\left(\rho_{i}\right),
$$

где $\varphi_{i j}$ представляет парную энергию между атомами $i$ и $j$, отделенными друг от друга расстоянием $r_{i j}$, а $F_{i}$ энергия вложения атома $i$ в локальном местоположении с электронной плотностью $\rho_{i}$. Электронную плотность можно рассчитать по формуле:

$$
\rho_{i}=\sum_{j, j \neq i} f_{j}\left(r_{i j}\right),
$$


где $f_{j}\left(r_{i j}\right)$ - электронная плотность на участке атома $i$ находящегося на расстоянии $r_{i j}$ от атома $j$.

Температура расчетной ячейки задавалась путем присвоения атомам случайных скоростей в соответствии с распределением Максвелла-Больцмана для указанной температуры. Шаг численного интегрирования уравнений движения равнялся 1 фс.

В настоящей работе исследование проводилось на расчетной ячейке, моделирующей двудольный биметалл $\mathrm{Ni}-\mathrm{Al}$, имеющей форму прямоугольного параллелепипеда, число атомов и размер ячейки варьировались с целью выявления влияния размерного фактора на поведение биметалла при прохождении ударной волны. Линейные размеры расчетной ячейки вдоль осей $X$ и $Y$ варьировались от 6,5 до 65 нм, а толщина слоя Al составляла от 4,2 до 15,45 нм. При этом расчетная ячейка содержала от $4,5 \cdot 10^{3}$ до $2,3 \cdot 10^{6}$ атомов.

Для получения двудольных модельных биметаллов два исходных однокомпонентных кристалла разных металлов в виде прямоугольных параллелепипедов размещались на расстоянии порядка 2,5 А друг от друга. После чего производилась релаксация структуры (рис. 1). Вдоль всех осей задавались свободные граничные условия. В процессе релаксации происходил разогрев расчетного блока до нескольких десятков Кельвин. В виду наличия свободных граничных часть атомов вблизи поверхности перемещалась на соседний метал.

Рассматривалось три ориентации биметаллических частиц в пространстве:

I. ось $X$ направлена вдоль кристаллографического направления $<10 \overline{1}>$, ось $Y-$ вдоль $<010>$, а $Z-$ вдоль $<101>$,

II. ось $X$ направлена вдоль кристаллографического направления $<100>$, ось $Y-$ вдоль $<010>$, а $Z-$ вдоль $<001>$,

III. ось $X$ направлена вдоль кристаллографического направления $<1 \overline{1} 0>$, ось $Y-$ вдоль $<11 \overline{2}>$, а $Z-$ вдоль $<111>$.

На границе раздела металлов формировалась сетка дислокаций несоответствия, обусловленная различием параметров решетки компонент ДБМ частицы и ориентацией в пространстве ее компонент (рис. 2), визуа-

лизированная посредством OVITO [24]. В процессе релаксации структуры границы ДБМ часть дислокаций сместилась вглубь Al, что вызвано меньшей энергией связи между атомами Al-Al, чем между $\mathrm{Ni}-\mathrm{Ni}$ и $\mathrm{Ni}-\mathrm{Al}$. Такая конфигурация позволила рассмотреть границу раздела с различной плотностью дислокаций несоответствия и направлением плотноупакованных рядов атомов.

Особенностями ударной волны является большая амплитуда атомных смещений, а также малая ширина фронта, соизмеримая с параметром решетки кристалла. Кроме того ударные волны распространяются в веществе со скоростями превышающими скорость звука.

Поэтому для создания волны, группе атомов в приграничной области расчетной ячейки (один крайний атомный слой) присваивалась скорость, превышающая скорость звуковых волн с материала, вдоль кристаллографического направления соответствующего оси $Z$. Скорость атомам присваивалась таким образом, чтобы скорость распространения волны была в интервале от $c$ до $1,5 c$, оцениваемая по прохождению фронтом волны десяти межатомных расстояний. В результате, формировалась ударная волна, проходящая через границу раздела биметалла $\mathrm{Ni}-\mathrm{Al}$.

Особое внимание было уделено ударной волне, распространяющейся вдоль плотноупакованного направления, т.к. в этом случае имеет место механизм фокусировки энергии, сферическая волна трансформируется во фрагменты плоских волн, распространяющихся именно вдоль плотноупакованных направлений [25-26].

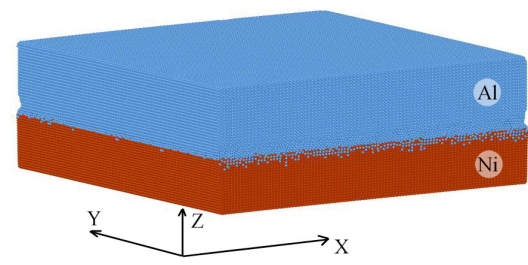

Рис. 1. Объемный вид двудольного биметаллического блока $\mathrm{Ni}$-Al, содержащего $8,34 \cdot 10^{5}$ атомов.

Fig. 1. The bulk of the bimetallic Ni-Al block containing $8,34 \cdot 10^{5}$ atoms.

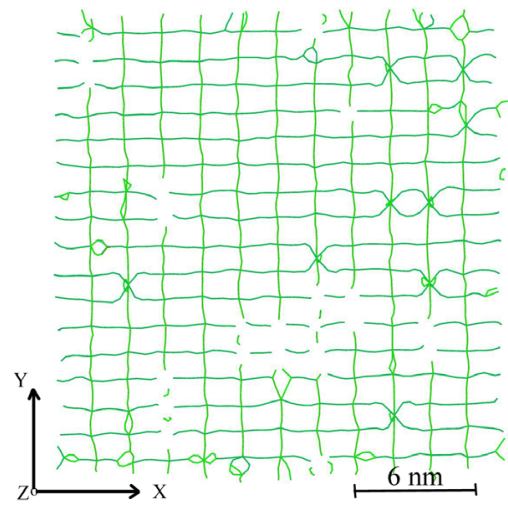

a

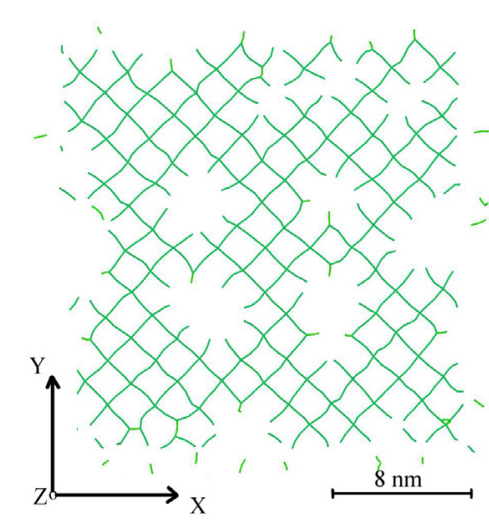

b

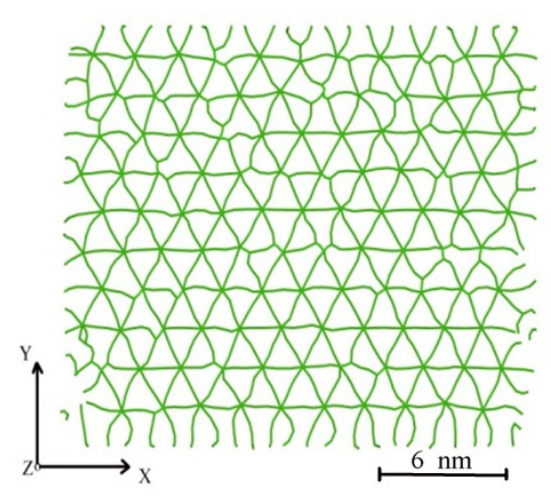

c

Рис. 2. Сетка дислокаций несоответствия на границе раздела двудольных биметаллических частиц Ni-Al, a) для случая I, b) для случая II, c) для случая III.

Fig. 2. The mismatch dislocation grid at the interface of bipartite bimetallic Ni-Al particles, a) for case I, b) for case II, c) for case III. 


\section{3. Обсуждение результатов}

Как показано на 2D моделях биметаллов [27], прохождение ударных волн сопровождается их дифракцией на ядрах дислокаций несоответствия вблизи границы раздела металлов. При достаточной энергии волны формировались зародыши пор в $\mathrm{Al}$. Сетка дислокаций несоответствия для техмерного случая имеет сложную структуру, поэтому распределение интерференционных максимумов (минимумов) также имеет более сложный вид.

Рассмотрим два направления распространения ударных волн. В первом волна инициировалась со стороны Ni. Ее скорость варьировалась от $48 \AA /$ пс до $72 \AA /$ пс, в соответствии с табличным значением скорости звука в кристаллите Ni [28].

B случае ориентации I, направление распространение волны соответствовало плотноупакованному направлению в кристалле. При такой конфигурации волна проходит границу раздела металлов с минимальными искажениями фронта и потерями энергии (рис. За). Оценка показала, что до поверхности $\mathrm{Al}$ доходит порядка 45\% энергии первоначальной волны, при этом происходит отрыв крайних атомов $\mathrm{Al} \mathrm{c}$ образованием нанокластеров, первоначальные размеры которых соответствуют линейным размерам ячеек сетки дислокации несоответствия (рис. 3b). Дальнейшая эволюция образовавшихся кластеров $\mathrm{Al}$ является отдельной задачей и будет рассмотрена нами в последующих работах. После отрыва атомов Al формировалась характерная поверхность ДБМ частицы (рис. 3c). Форма поверхности обусловлена наличием свободных граничных условий.

При скоростях ударной волны более $60 \AA ̊$ /пс формировались зародыши пор вблизи границы раздела ДБМ частицы на стороне Al. Дальнейшая релаксация структуры приводила к схлопыванию образовавшихся пор. Процесс эволюции пористой структуры достаточно быстротечен. Основной тенденцией является объединение пор от краев к центру с последующим схлопыванием.

Более подробно эволюцию пор рассмотрим для III случая ориентации компонент биметалла. Для всего интервала скоростей имело место формирование зародышей пор вблизи границы металлов. Как показали эксперименты, начальная скорость ударной волны влияла на размер зародышей пор, которые формировались на стороне $\mathrm{Al}$ (рис. 4.). На графике приведены значение максимального линейного размера поры вдоль оси $Z$ для всех трех случаев ориентации компонент ДБМ.

Размеры зародышей пор для случая III были значительно больше, чем для других вариантов ориентации компонент биметалла при той же начальной скорости волны, т.к. имело место более плотное расположение дислокаций несоответствия на границе раздела металлов. Наиболее ярко это проявилось для скоростей более $60 \AA ̊$ /пс. Также рассеиванию энергии ударной волны после прохождения границы способствовало не плотноупакованное направление в кристалле.

При этом распределение пор и скорость их схлопывания в биметалле зависели от линейных размеров, рассматриваемой модели частицы. Отметим, что для ча-
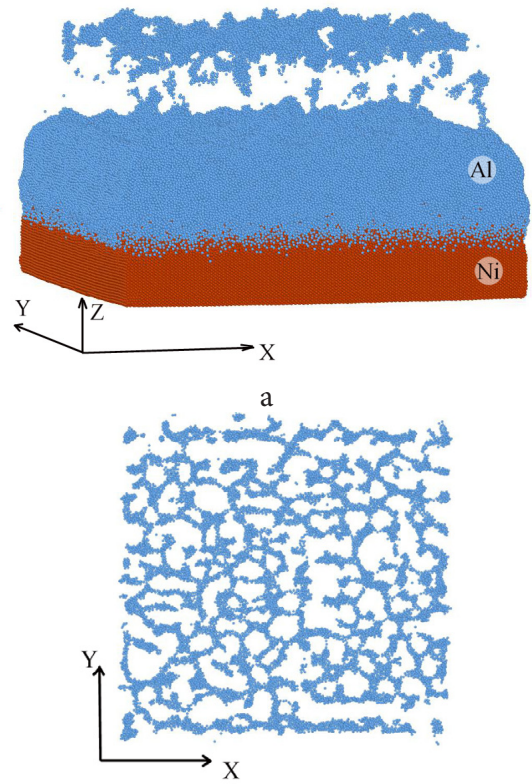

b

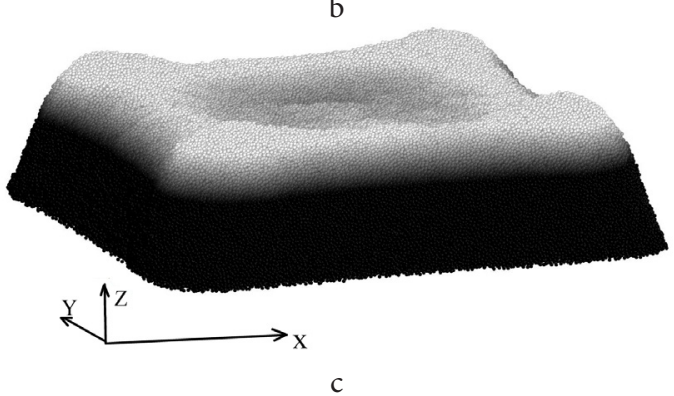

Рис. 3. Биметаллическая двудольная частица $\mathrm{Ni}-\mathrm{Al}\left(8,34 \cdot 10^{5}\right.$ атомов), ориентированный для случая I, а) объемный вид ДМБ $\mathrm{Ni}-\mathrm{Al}$ после прохождения ударной волны, b) визуализация образовавшихся кластеров $\mathrm{Al}, \mathrm{c})$ рельеф поверхности после отделения нанокластеров $\mathrm{Al}$ через 5 пс релаксации.

Fig. 3. Bimetallic bipartite particle $\mathrm{Ni}-\mathrm{Al}\left(8,34 \cdot 10^{5}\right.$ atoms $)$ oriented for case I, a) three-dimensional view of the Ni-Al nanoclusters after the passage of the shock wave, $b$ ) visualization of the formed $\mathrm{Al}$ clusters, c) surface relief after separation of $\mathrm{Al}$ nanoclusters after 5 ps of relaxation.

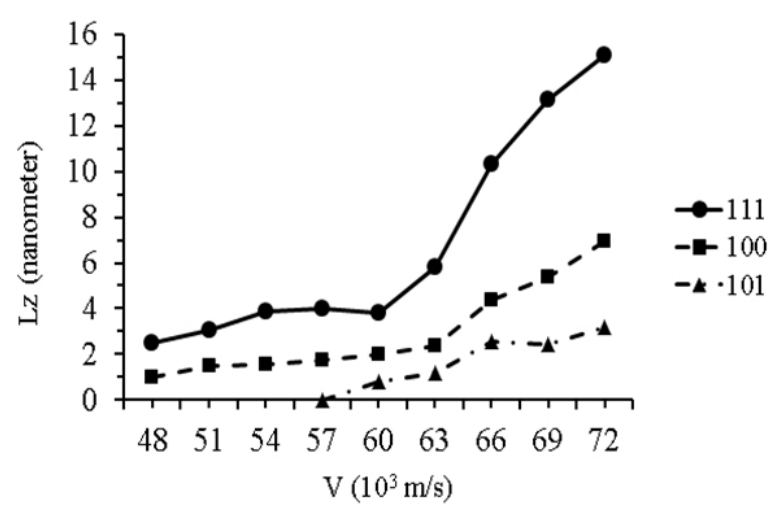

Рис. 4. Зависимость максимального линейного размера поры вдоль оси $Z$ от начальной скорости ударной волны для различных направлений. Линейные размеры биметалла вдоль осей $X$ и $Y$ составляли 41,8 нм, вдоль оси $Z$ 14,1 нм.

Fig. 4. Dependence of the linear size of the pore along the $Z$ axis on the initial velocity of the shock wave for different directions. The linear dimensions of the bimetal along the $X$ and $Y$ axes corresponded to $41.8 \mathrm{~nm}$, along the $Z$ axis of $14.1 \mathrm{~nm}$. 
стиц менее 8 нм поры не формировались. Это связано с влиянием свободной поверхности биметалла и меньшим количеством дислокаций на межфазной границе. Для биметаллов размером от 8 до 15 нм происходит формирование двух-трех пор расположенных в областях первого и второго интерференционного минимума ударной волны на дислокациях несоответствия. Для больших размеров ячейки количество зародышей пор увеличивалось, пример эволюции данной структуры представлен на рис. 5.

Размер ДБМ частиц влиял на время схлопывания пор. На рис. 6 приведена такая зависимость для случая ориентации компонент биметалла III от линейных размеров ячейки вдоль осей $X$ и $Y$. Толщина слоя Al была постоянной для всех экспериментов и составляла 5,84 нм, скорость волны $60 \AA$ А пс.

Влияние свободной поверхности уменьшается при увеличении линейных размеров ячейки, однако для частиц в том числе более 60 нм оно имеет место.

Далее рассматривалось влияние толщины слоя $\mathrm{Al}$ на возможность формирования пор, результаты представлены на рис. 7. Линейные размеры ячейки вдоль осей $X$ и $Y$ сохранялись равными 41,8 нм, толщина слоя $\mathrm{Al}$ изменялась от 4,2 до 15,45 нм. Полученные результа-
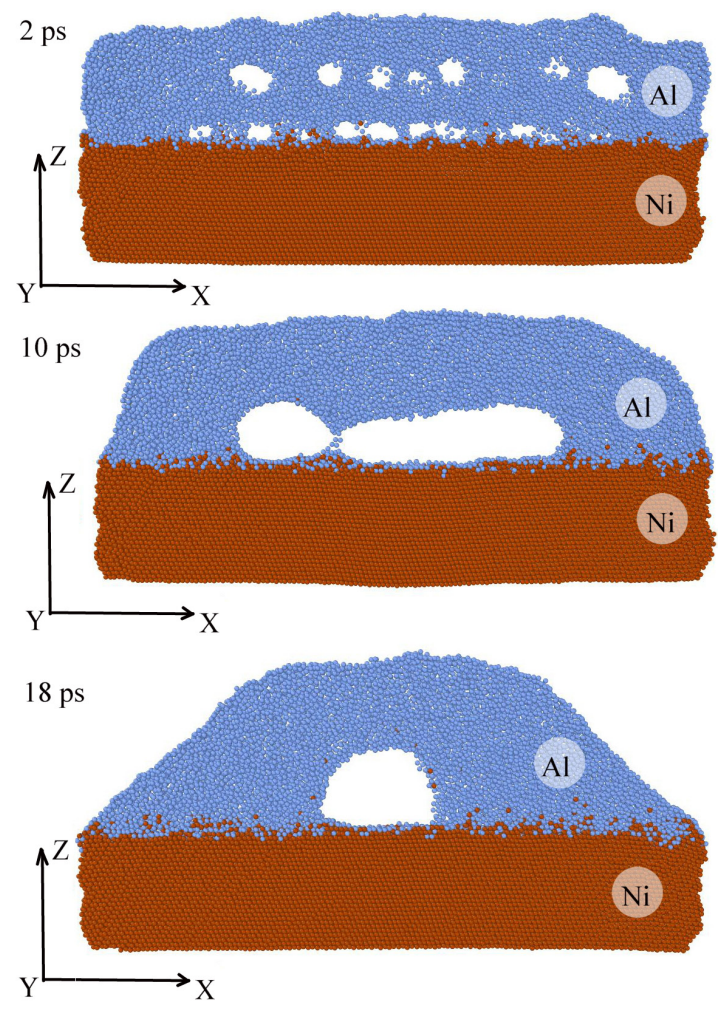

Рис. 5. Эволюция пор в двудольном биметаллическом кластере ориентации III после прохождения ударной волны со скорость $60 \AA$ Алс, толщина визуализированной плоскости 4 нм. Линейные размеры биметалла вдоль осей $X$ и $Y$ соответствовали 41,8 нм, вдоль оси $Z$ 14,1 нм.

Fig.5. Evolution of pores in a bipartite bimetallic cluster of orientation III after the passage of the shock wave with a velocity of $60 \AA / p s$, a thickness of the visualized plane of $4 \mathrm{~nm}$. The linear dimensions of the bimetal along the $X$ and $Y$ axes corresponded to $41.8 \mathrm{~nm}$, along the $Z$ axis $14.1 \mathrm{~nm}$. ты свидетельствуют, что при толщине более 15 нм формирование пор не происходит. Несмотря на расплав $\mathrm{Al}$ вблизи границы раздела металлов, энергии волны не достаточно для создания свободного объема за счет смещения атомов $\mathrm{Al}$ вдоль оси $Z$.

Таким образом, возможность формирования зародышей пор в значительной степени определяются размерами двудольных биметаллических частиц.

В случае инициирования ударной волны на стороне $\mathrm{Al}$, скорость волны задавалась в диапазоне от $50 \AA /$ пс до $76 \AA$ /пс, в соответствии со скоростью звука в $\mathrm{Al}$ [27]. Несмотря на изменение направления распространения ударной волны, зародыши пор формировались на стороне Al. Это обусловлено частичным отражением ударной волны от границы металлов и меньшей энергией связи атомов Al друг с другом. Ориентация компонент биметалла влияла на размеры зародышей пор аналогичным образом, как и при инициировании волны co стороны Ni. В случае распространения ударной волны вдоль плотноупакованного направления размер пор был минимальным. Таким образом, независимо от направления ударной волны возможно формирование зародышей пор только на стороне $\mathrm{Al}$ вблизи границы раздела металлов.

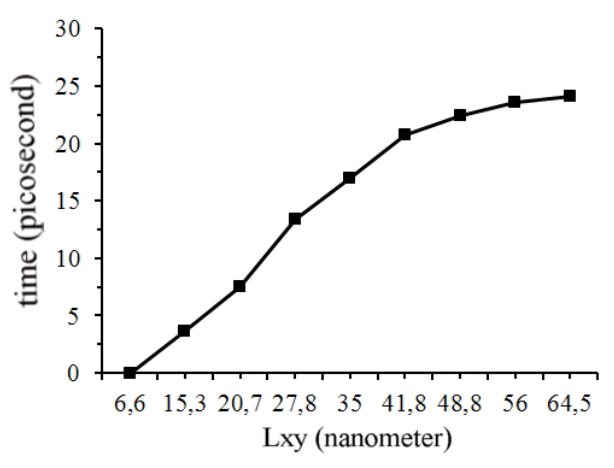

Рис. 6. Зависимость времени схлопывания пор от линейных размеров биметалилческого кластера вдоль осей $X$ и $Y$ для случая III.

Fig. 6. Dependence of pore collapse time on the linear dimensions of a bimetallic cluster along the $X$ and $Y$ axes for case III.

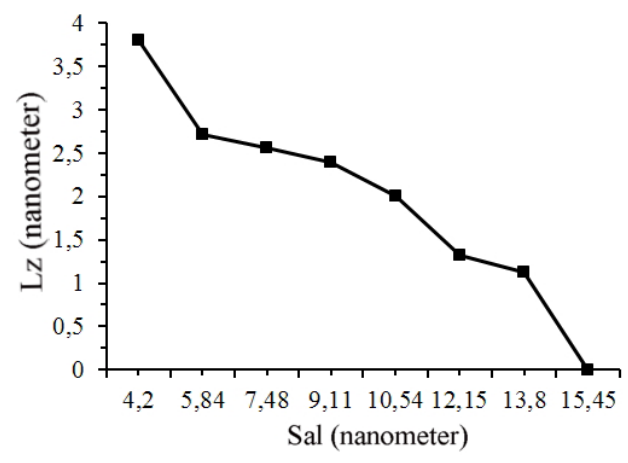

Рис. 7. Зависимость максимальных линейных размеров пор вдоль оси $Z$ от толщины слоя $\mathrm{Al}$, линейные размеры вдоль осей $X$ и $Y 41,8$ нм.

Fig. 7. The dependence of the maximum linear pore sizes along the $Z$ axis on the thickness of the $\mathrm{Al}$ layer, the linear dimensions along the $X$ and $Y$ axes are $41.8 \mathrm{~nm}$. 


\section{4. Выводы}

Компьютерное моделирование, проведенное методом молекулярной динамики, показало существенное влияние ударной волны на структуру границы ДБМ $\mathrm{Ni}-\mathrm{Al}$ и поверхность кристалла. Установлено, что одним из определяющих факторов формирования зародышей пор вблизи границы раздела $\mathrm{Ni}-\mathrm{Al}$ является взаимная ориентация металлов, их размер и направление прохождения ударной волны. При распространении волны, инициированной на стороне $\mathrm{Ni}$ вдоль плотноупакованного направления, кроме формирования пор возможен отрыв части атомов с поверхности $\mathrm{Al}$ с последующим формированием из них кластеров. Это обусловлено тем, что при прохождении границы раздела металлов фронт ударной волны испытывает минимальные искажения, и значительная часть энергии волны доходит до поверхности кристалла Al. B случае ориентации кристалла, когда волна распространяется не вдоль плотноупакованного направления, основная часть энергии рассеивается вблизи границы раздела металлов и приводит к формированию зародышей пор. Формирование пор в большей степени зависят от размеров частиц биметалла. В случае инициирования ударной волны на стороне $\mathrm{Al}$, наблюдались аналогичные эффекты, однако, поры формировались на стороне Al, как и в предыдущем случае. Такое расположение пор обусловлено меньшей энергией связи между атомами $\mathrm{Al}$, чем между $\mathrm{Ni}-\mathrm{Ni}$ и $\mathrm{Ni}-\mathrm{Al}$.

Полученные результаты могут быть полезны при ультразвуковой обработке материалов, наноинженирии, а также в радиационном материаловедении.

Благодарность/Acknowledgements. ПВЗ благодарит за финансовую поддержку РНФ, проект № 16-12-10175, МДС и ГМП выражает благодарность Министерству образования и науки РФ базовой части государственного задания (проект № 3.4820.2017/БЧ)

\section{Литература/References}

1. A.A. Bykov. Development of production of bimetals. Metallurgist: scientific and technical and industrial journal. 9, 61-65 (2009). (in Russian) [А.А. Быков. Развитие производства биметаллов. Металлург: научно-технический и производственный журнал. 9, $61-65$ (2009).]

2. I. N. Pavlov, V.N. Lebedev, A. G. Kobelev et al. Layered compositions. Moscow, Metallurgiya. (1986) 216 p. (in Russian) [И.Н. Павлов, В.Н. Лебедев, А.Г. Кобелев и др. Слоистые композиции. Москва, Металлургия. 1986. 216 c.]

3. O.G. Ellert, M.V. Tsodikov, S.A. Nikolaev, V.M. Novotortsev. Bimetallic nanoalloys in heterogeneous catalysis industrially important reactions: synergism and structural organization of active components. Advances in Chemistry. 83 (8), $718-732$ (2014). (in Russian) [О. Г. Эллерт, М.В.Цодиков, С. А. Николаев, В. М. Новоторцев. Биметаллические наносплавы в гетерогенном катализе промышленно важных реакциях: синергизм и структурная организация активных компонентов. Успехи Химии. 83 (8), 718 - 732 (2014).]

4. U. Sanyal, D. Therese, R. Jagirdar Balaji. Dalton Trans. V. 42, Issue 19, 7147 - 7157 (2013).

5. S.E. Eliana Misi, A. Ramli, F.H. Rahman. Journal of Applied Sciences. 11, 1297 - 1302 (2011).

6. Yinlong Shen, Weiguang Gong, Baicun Zheng, Lei Gao Ni. Applied Catalysis B: Environmental. V. 181, 769 - 778 (2016).

7. Fabien Massicot, Raphaël Schneider, Yves Fort, Sandra Illy-Cherrey, Olivier Tillement. Tetrahedron. V. 56, Issue 27, $4765-4768$ (2000).

8. D. V. Shirokorad, G. V. Kornich, S. G. Bug. Simulation of the interaction of bipartite bimetallic clusters with lowenergy argon clusters. Solid State Physics. V. 59, Issue 1, $189-199$ (2017). (in Russian) [Д.В. Широкорад, Г.В. Корнич, С.Г. Буга. Моделирование взаимодействия двудольных биметаллических кластеров с низкоэнергетическими кластерами аргона. Физика твердого тела. Т. 59, вып. 1, 189 - 199 (2017).]

9. A. J. Gavens, D. Van Heerden, A. B. Mann, M.E. Reiss, T. P. Weihs. J. Appl. Phys. 87, 1255 (2000).

10. M.D. Wiemer, J. Braeuer, D. Wunsch, T. Gessner. ECS Trans. 33, 307 (2010).

11. A. V. Markidonov, M.D. Starostenkov, M.N. Smirnova Russian Physics Journal V. 58, Issue 6, pp 828 - 832 (2015)

12. A.V. Markidonov, M.D. Starostenkov Bulletin of Voronezh State University. Series: physics, mathematics 1. 14-23 (2016) (in Russian) [А.В. Маркидонов, М. Д. Старостенков Коалесценция вакансионных нанопор в кристалле с гцк решеткой под воздействием ударных послекаскадных волн. Вестник воронежского государственного университета. серия: физика, математика. 1. 14-23 (2016)]

13. A. V. Markidonov, M.D. Starostenkov On the possibility of homogeneous nucleation of a pore in a grain boundary region under the influence of shock aftercascade waves. Issues of atomic science and technology. Series: Mathematical modeling of physical processes. V.3 pp. 37 - 46 (2016) (in Russian) [А. В. Маркидонов, М.Д. Старостенков О возможности гомогенного зарождения поры в зернограничной области под воздействием ударных послекаскадных волн. Вопросы атомной науки и техники. Серия: Математическое моделирование физических процессов. Т. 3. С. $37-46$ (2016)]

14. V.V. Ovchinnikov Phys. Usp. 51. 955 - 964 (2008)

15. W. M. Howard, J. D. Molitoris AIP Conference Proceedings 845, 319 (2006); doi: http://dx.doi.org/10.1063/1.2263327

16. C. Montross, T. Wei, L. Ye, G. Clark, Y. Mai: Vol. 10. Issue 10, P. 1021 - 1036 (2002)

17. A. Molinari, G. Ravichandran. Fundamental structure of steady plastic shock waves in metals. Journal of Applied Physics, 95 (4). pp. 1718 - 1732. (2004)

18. A. V. Markidonov, M.D. Starostenkov, P.V. Zakharov, O. V. Obidina. Pore formation in a fcc crystal under the influence of shock after-cascade waves. Fundamental problems of modern materials science. 12 (2), 231-240 (2015). (in Russian) [А. В. Маркидонов, М.Д. Старостенков, П.В. Захаров, О.В. Обидина. Порообразование в ГЦК кристалле под воздействи- 
ем ударных послекаскадных волн. Фундаментальные проблемы современного материаловедения. 12 (2), $231-240$ (2015).]

19. A. V. Sannikov, G.M. Poletaev, A.A. Soskov, M.D. Starostenkov. Interaction of point defects with coherent interphase boundaries of Ni-Al (100) and (111). Fundamental problems of modern materials science. 11 (3), 317 - 321 (2014). (in Russian) [A. В. Санников, Г.М. Полетаев, А.А. Сосков, М.Д. Старостенков. Взаимодействие точечных дефектов с когерентными межфазными границами $\mathrm{Ni}-\mathrm{Al}$ (100) и (111). Фундаментальные проблемы современного материаловедения. 11 (3), 317 - 321 (2014).]

20. A.V. Sannikov, G.M. Poletaev, V.R. Mikryukov, M.D. Starostenkov, A. A. Soskov. Atomic structure and diffusion permeability of the interphase boundaries of Ni$\mathrm{Al}, \mathrm{Cu}-\mathrm{Au}, \mathrm{Ni}-\gamma \mathrm{Fe}$. Proceedings of universities. Ferrous metallurgy. V. 57, no. 8, 56-59 (2014). (in Russian) [А.В. Санников, Г.М. Полетаев, В.Р. Микрюков, М.Д. Старостенков, А. А. Сосков. Атомная структура и диффузионная проницаемость межфазных границ $\mathrm{Ni}-\mathrm{Al}, \mathrm{Cu}-\mathrm{Au}, \mathrm{Ni}-\gamma \mathrm{Fe}$. Известия вузов. Черная металлургия. Т. 57, № 8, 56- 59 (2014).]

21. G. M. Poletaev, A.V. Sannikov, A.A. Berdychenko, M.D. Starostenkov. Materials Physics and Mechanics. V.22, no. 1, 15 - 19 (2015).

22. LAMMPS Molecular Dynamics Simulator http://lammps.sandia.gov/

23. J.E. Angelo, N.R. Moody, and M. I. Baskes, Trapping of hydrogen to lattice-defects in nickel // Modelling Simul. Mater. Sci. Engr. 3, 289- 307 (1995).

24. Open visualization tool (OVITO) http://www.ovito.org/ 25. V.G. Chudinov, R. M. J. Cotterill, V. V. Andreev. Physica Status Solidi (a). V.122, no.1, $111-120$ (1990).

26. A.M. Iskandarov, N.N. Medvedev, P.V. Zakharov, S. V. Dmitriev. Computational Materials Science. V. 47, $429-431$ (2009).

27. P. V. Zakharov, A.V. Markidonov, M.D. Starostenkov, G. M. Poletaev, A.M. Eremin, O. V. Obidina. Effect of shock after-cascade waves on the interphase boundary of bimetals Ni-Al, Ni-Fe. Fundamental problems of modern materials science. V. 13, no. 1, 77 - 83 (2016). (in Russian) [П.В. Захаров, А. В. Маркидонов, М.Д. Старостенков, Г. М. Полетаев, А. М. Ерёмин, О. В. Обидина. Влияние ударных послекаскадных волн на межфазную границу биметаллов Ni-Al, Ni-Fe. Фундаментальные проблемы современного материаловедения. Т. 13, № 1, $77-83$ (2016).]

28. N.I. Koshkin, M.G. Shirkevich. The handbook on elementary physics is the fifth edition, revised. Moscow, Science. (1972) 256 p. (in Russian) [Н.И. Кошкин, М.Г. Ширкевич. Справочник по элементарной физике издание пятое, переработанное.Москва, Наука. 256 c. (1972)] 